\title{
Excision repair cross complementation group 1 is a chemotherapy-tolerating gene in cisplatin-based treatment for non-small cell lung cancer
}

\author{
SHOUFENG WANG ${ }^{*}$, HONG PAN ${ }^{*}$, DESEN LIU, NAIQUAN MAO, CHUANTIAN ZUO, LI LI, \\ TONG XIE, DINGMING HUANG, YAOYUAN HUANG, QI PAN, LI YANG and JUNWEI WU \\ Department of Thoracic Surgery, Affiliated Tumor Hospital of Guangxi Medical University, \\ Nanning, Guangxi 530021, P.R. China
}

Received September 28, 2014; Accepted November 20, 2014

DOI: $10.3892 /$ ijo.2014.2784

\begin{abstract}
This study aimed to evaluate the biological functions of excision repair cross complementation goup 1 (ERCC1) in cell proliferation, cell cycle, invasion and cisplatin response of non-small cell lung cancer (NSCLC) cells. Firstly, ERCC1 gene was successfully transfected into H1299 cells by gene cloning and transfection techniques. Then, cell proliferation was determined with the cell growth curve and colony-forming assays. Flow cytometry (FCM) was employed to investigate the cell cycle distribution. The ability of cell invasion was estimated by means of Matrigel invasion assays. Response of NSCLC cells to cisplatin was detected utilizing MTT assays, and the intracellular drug concentrations were determined by the high performance liquid chromatography (HPLC) analysis. Expression of the two cell membrane proteins, $\mathrm{P}$-glycoprotein ( $\mathrm{P}-\mathrm{gp}$ ) and multidrug resistanceassociated protein (MRP), was also evaluated utilizing FCM technique. By contrast, ERCC1 expression in the NSCLC A549 cells was silenced by small interfering RNA (siRNA) through RNAi technique. In addition, the cytotoxic effect of cisplatin on A549 cells was detected by MTT assays. In the present study, the results demonstrated that ERCC1 had no effect on cell proliferation, cell cycle and the ability of invasion, but showed significant impact on cisplatin response of the NSCLC H1299 cells. Furthermore, siRNA-induced suppression of ERCC1 evidently enhanced sensitivity to cisplatin of NSCLC A549 cells. Therefore, it is confirmed that ERCC1 is a chemotherapy-tolerating gene and a promising predictor in tailoring chemotherapy of NSCLC.
\end{abstract}

Correspondence to: Dr Hong Pan, Department of Thoracic Surgery, Affiliated Tumor Hospital of Guangxi Medical University, Hedi Road 71, Nanning, Guangxi 530021, P.R. China

E-mail: panhong0771@126.com

*Contributed equally

Key words: non-small cell lung cancer, excision repair cross complementation group 1, cisplatin resistance

\section{Introduction}

Lung cancer is the leading cause of cancer-related deaths worldwide, with $\sim 1.5$ million new cases diagnosed each year (1). Approximately $85 \%$ of all cases of lung cancer is non-small cell lung cancer (NSCLC) which is responsible for $>1.2$ million deaths worldwide each year $(1,2)$. Current outcomes of NSCLC treatment are disappointing with dismal prognosis, and the overall 5-year survival rates remain $\sim 15 \%$ for the past few decades (3). This is because $\sim 55 \%$ of patients present with advanced stage at time of diagnosis (4). Platinumbased chemotherapy, is currently the mainstay of the advanced NSCLC treatment (5).

Cisplatin [Cis-diammine-dichloroplatinum (II), DDP] and its analogue carboplatin are the most commonly used platinum agents in the platinum-based chemotherapy of NSCLC $(6,7)$. They are heavy metal complexes, and present their therapeutic cytotoxic properties by covalently binding to DNA to form intra- and interstrand cross-links which interfere with normal DNA replication and transcription $(8,9)$. Without efficient DNA repair, the platinum-induced DNA damage eventually leads to cell apoptosis (5). Although the platinum containing agents greatly increase the effectiveness of NSCLC treatment compared with other drugs, platinum-based chemotherapy has apparently reached a therapeutic plateau with limited response to treatment as well as little improvement of survival for patients $(10,11)$, due to the tumors rapidly developing acquired drug resistance which has not yet been overcome (12). Many published reports suggest that the emergence of platinum resistance, not only intrinsic, but also acquired primarily attribute to the nucleotide excision repair (NER) system $(6,13)$.

NER system, a highly versatile and sophisticated system for DNA damage removal, is the primary repair pathway for DNA helix-distorting lesions induced by platinum agents $(2,14)$. High DNA repair capacity of NER pathway certainly contributes greatly to drug resistance in the platinum-based chemotherapy of NSCLC. DNA repair capacity of NER pathway can be represented by the expression level of excision repair cross-complementation group 1 (ERCC1) which is one of the most important members of the pathway (15). It has been reported that ERCC1 together with xeroderma 
pigmentosum group $\mathrm{F}$ (XPF) forms the ERCC1-XPF complex to nick the damaged DNA strand at the 5' sit of the helixdistorting platinum lesion, which is considered as the essential rate-limiting step in the NER process $(14,16)$.

Recently, accumulated preclinical and clinical studies have demonstrated that ERCC1 could be as a prognostic factor (information on the patients overall cancer outcome, regardless of therapy), predictive (information on the effect of a therapeutic intervention) and a potential therapeutic target in cancer, including NSCLC $(13,17)$. In these studies, among patients who did not receive chemotherapy, those with ERCC1-positive tumors had longer survival than those with ERCC1-negative tumors (18), however, for the patients with ERCC1-negative tumors, they had a distinctly higher response rate (19) and attained benefit from platinum-based chemotherapy with significantly prolonged survival, but patients with ERCC1-positive tumors did not $(18,20,21)$. In some other studies, inconsistently, ERCC1 expression was not associated with platinum response (22) or survival (23) in NSCLC patients.

It is still controversial whether ERCC1 should be used as a predictor to guide clinical personalized chemotherapy or not, due to the inconsistence of clinical outcomes (24). Multicenter clinical trails with larger sample size, such as the International Adjuvant Lung Cancer Trial Biologic Program (IALT-Bio) and the Lung Adjuvant Cisplatin Evaluation Biologic Program (LACE-Bio) (25-27), should be conducted for the application of ERCC1 in clinic. Nevertheless, studies on biomarkers like ERCC1 provides an onset for overcoming drug resistance and tailoring chemotherapy in NSCLC treatment. Our previous retrospective studies have indicated that ERCC1 is a potential candidate biomarker to predict tailoring chemotherapy of NSCLC (28). In the present study, we aim to further reveal the biological functions of ERCC1 in cell proliferation, cell cycle, invasion and cisplatin resistance in NSCLC cells by gene cloning, cell transfection and RNAi techniques, to provide more evidence for the utilization of ERCC1 as a biomarker in the customized chemotherapy of NSCLC.

\section{Materials and methods}

Material, vectors and reagents. Tissue sample used for the cloning of ERCC1 gene was from the redundant tissue of surgical operation performed on a patient with brain injury. The patient gave written informed consent before enrolment. The present study was carried out following international and national regulation and approved by the Ethics Committee of the Affiliated Tumor Hospital of Guangxi Medical University. PMD18-T vector used for TA cloning, PCDNA3.1 vector for cell transfection and pSilencer 4.1-CMV-neo vector for RNAi were obtained from Takara (Tokyo, Japan), Invitrogen (Carlsbad, CA, USA) and Ambion (Austin, TX, USA), respectively. TRIzol reagents, RevertAid ${ }^{\mathrm{TM}}$ First Strand cDNA Synthesis kit and Lipofectamine 2000 were from Invitrogen. Ex Taq DNA polymerase, restriction endonucleases Bam $\mathrm{H} 1$ and EcoR1, and T4 DNA ligase were from Takara. Plasmid Mini kit was from Qiagen (Duesseldorf, Germany). M-per Mammalian Protein Extraction kit, Bradford protein assay kit and fluorescein isothiocyanate (FITC) reagents were purchased from Pierce (Rockford, IL, USA). Goat anti-human antibody ERCC1 and goat anti-human antibody $\beta$-actin used for western blot assays were from NeoMarkers (Fremont, CA, USA), and the secondary rabbit anti-goat antibody was from Fuzhou Maixin Biotech. Co., Ltd. (Fuzhou, China). Giemsa stain for colony-forming assays, propidium lodide (PI) fluorescence dye and RNase A used in the cell cycle assays were from Sigma (St. Louis, MO, USA) and Sango (Shanghai, China), respectively. All the reagents for high performance liquid chromatography (HPLC) assays were obtained from Merck (Darmstadt, Germany). Mouse anti-human monoclonal antibody (McAb) of P-glycoprotein (P-gp) and multidrug resistance-associated protein (MRP), as well as the corresponding secondary goat anti-mouse antibody used in the flow cytometry (FCM) were from Invitrogen.

Cell lines, cell culture and drugs. Human NSCLC cell line H1299 was presented by Dr Zhe Zhang from Karolinska Institutet of Sweden. Human NSCLC cell line A549 was purchased from the cell bank of Peking Union Medical College (Beijing, China). NSCLC cells were grown in RPMI-1640 medium supplemented with $10 \%$ fetal bovine serum (FBS), $100 \mathrm{U} / \mathrm{ml}$ penicillin and $100 \mu \mathrm{g} / \mathrm{ml}$ streptomycin at the final concentration and maintained in a humidified atmosphere containing $5 \% \mathrm{CO}_{2}$ at $37^{\circ} \mathrm{C}$. Cell culture reagents and $\mathrm{FBS}$ were obtained from Gibco (BRL, Long Island, NY, USA), antibiotics of penicillin and streptomycin were from Shandong Qilu Pharmaceutical Factory (Shandong, China), and Geneticin (G418) was from Sigma. Cisplatin and adriamycin (ADM) were purchased from Shandong Qilu Pharmaceutical Factory and Zhejiang Haimen Pharmaceutical Factory (Zhejiang, China), respectively.

Acquisition of the ERCC1 gene. ERCC1 gene was obtained from the tissue sample by reverse transcription-PCR (RT-PCR) technique. In brief, the tissue sample was incised and immediately put into liquid nitrogen. Total RNA was isolated from the samples using TRIzol reagent according to the manufacturer's instructions. Approximately $0.5-5 \mu \mathrm{g}$ of total RNA together with random hexamers were used for the cDNA synthesis through RT-PCR with RevertAid ${ }^{\mathrm{TM}}$ First Strand cDNA Synthesis kit. The final cDNA was used for the following PCRs. ERCC1 primers (forward, 5'-CGCGGATTCATGGA CCCTGGGAAGGACAAAG-3'; reverse, 5'-CCGGAATTCT CAGGGTACTTTCAAGAAGGG-3') were designed with Primer 5 software and synthesized in Sangon Biotech Co., Ltd. PCR was performed in a $25-\mu 1$ solution including $200 \mathrm{nM}$ of the primers, $200 \mathrm{nM}$ of converted cDNA, $10 \mathrm{mM}$ deoxynucleotide triphosphates (dNTPs), $25 \mathrm{mM} \mathrm{MgCl}_{2}, 1.0 \mathrm{U}$ Ex Taq DNA polymerase and the PCR buffer. The amplification thermalcycling program consisted of 30 cycles of $94^{\circ} \mathrm{C}$ for $30 \mathrm{sec}$, $55^{\circ} \mathrm{C}$ for $30 \mathrm{sec}$ and $72^{\circ} \mathrm{C}$ for $45 \mathrm{sec}$. The obtained PCR products were separated by the $1 \%$ agarose gel electrophoresis and the correct one was purified to be used in the following vector construction.

Vector construction. To obtain accurate and adequate target gene for vector construction, TA cloning was performed in a system with a total volume of $10 \mu \mathrm{l}$, including the purified PCR product $4 \mu \mathrm{l}$, PMD18-T vector $1 \mu \mathrm{l}$, salt solution $1 \mu \mathrm{l}$ and $\mathrm{ddH}_{2} \mathrm{O} 4 \mu \mathrm{l}$. After 5-min incubation at room temperature, it 
was transformed into the competent cell TOP 10. Positive stains were selected with blue-white selection, and cultured. Then, the plasmid DNA was extracted with the Plasmid Mini kit according to the manufacturer's instructions. Target fragment in the plasmid DNA was isolated and inserted into the BamHI and EcoRI sites of PCDNA3.1 vector $(5.5 \mathrm{~kb})$ with the T4 DNA ligase. Thus, the connection product PCDNA3.1ERCC1 plasmid was obtained, and then was transfected into the competent cell TOP 10 again. Positive stains of TOP 10 were selected by the blue-white selection and identified by PCR to exclude false clones, and further confirmed by sequencing identification. Then, the PCDNA3.1-ERCC1 plasmid obtained through the above vector construction processes was used in the following cell transfection experiments.

ERCCl transfection into the H1299 cell line. Parental H1299 cells $0.5 \mathrm{ml}$ at the density of $0.6-1 \times 10^{5} / \mathrm{ml}$ were seeded in 6 -well plates per well and incubated at $37^{\circ} \mathrm{C}$ for $24 \mathrm{~h}$ until $80 \%$ confluent at the time of transfection. The transfection was performed using Lipofectamine 2000 according to the manufacturer's instructions with slight changes. Plasmid PCDNA3.1-ERCC1 obtained above was transfected into H1299 cells; PCDNA3.1 vehicle and PEGFP-N1 plasmid with the green fluorescent protein (GFP) gene were transfected into the H1299 cells as parallel controls; and H1299 cells treated with transfection reagents without any plasmids or vehicles were used as the negative control. The transfection procedures were as follows: firstly, DNA-Lipofectamine complexes were prepared for each transfection sample. DNA [3.0 $\mu \mathrm{l}(1.0 \mu \mathrm{g})]$ and $5 \mu \mathrm{l}$ Lipofectamine were mixed with $250 \mu \mathrm{l}$ antibiotic- and FBS-free medium respectively. After $20 \mathrm{~min}$ at room temperature the mixtures were combined for 15-20 min. The final mixture was the DNA-Lipofectamine complexes. Then, cells in each well were washed with the antibiotic- and FBS-free medium and added with the above DNA-Lipofectamine complexes to incubate for $5 \mathrm{~h}$ at $37^{\circ} \mathrm{C}$, then, $1 \mathrm{ml}$ medium containing FBS were added into each well and incubated for further $24 \mathrm{~h}$. The medium was then replaced by fresh normal medium and cells were cultured for $24-48 \mathrm{~h}$ to be used in the following screening and verification tests.

G418 cytotoxicity assays. G418 was used to select the positive cells transfected with PCDNA3.1-ERCC1 and PCDNA3.1 vehicle, as the PCDNA3.1 vector contains the anti-G418 gene. The selecting concentration of G418 was determined as follows: briefly, H1299 cells $\left(1 \times 10^{3}\right)$ grown in the antibiotics-free complete medium were seeded in 24-well plates and cultured till the cells attached. Then, they were treated with different concentrations of G418 (100-1,100 $\mu \mathrm{g} / \mathrm{ml}$ with $100 \mu \mathrm{g} / \mathrm{ml}$ for one gradient) and continuously incubated at $37^{\circ} \mathrm{C}$ in a humidified atmosphere containing $5 \% \mathrm{CO}_{2}$ for $10-14$ days. The minimum G418 concentration at which all the cells were killed was used as the selection concentration in the transfection assays.

Reverse transcription-quantitative PCR (RT-qPCR) assays. Total RNA was extracted with TRIzol reagent from the positive cells that had been screened by the G418 assays. cDNA was synthesized using the oligo(dt) primer according to the instructions of the RevertAid ${ }^{\mathrm{TM}}$ First Strand cDNA Synthesis kit. Subsequently, ERCC1 (441 bp) and PCDNA3.1 were amplified with the $\beta$-actin as an internal control. The primers were: ERCC1: 5'-GATGACCCAGATCATGTTTG-3' (forward), 5'-TGGAGTTGAAGGTAGTTTCG-3' (reverse); PCDNA3.1: 5'-CTGCTTACTGGCTTATC-3' (forward) and 5'-GAAAGGACAGTGGGAGTG-3' (reverse); $\beta$-actin: 5'-CAC CAACTGGGACGACAT-3' (forward) and 5'-A CAGCCTGG ATAGCAACG-3' (reverse). The amplification was performed in a $25-\mu 1$ solution containing $200 \mathrm{nM}$ of each of the primers, $200 \mathrm{nM}$ the converted cDNA, $10 \mathrm{mM}$ dNTPs, $25 \mathrm{mM} \mathrm{MgCl}_{2}$, 1.0 U Ex Taq DNA polymerase and the PCR buffer, in conjunction with a thermal-cycle program consisting of 30 cycles of $94^{\circ} \mathrm{C}$ for $30 \mathrm{sec}, 55^{\circ} \mathrm{C}$ for $30 \mathrm{sec}$ and $72^{\circ} \mathrm{C}$ for $45 \mathrm{sec}$. Finally, the PCR products were separated on a $1 \%$ agarose gel and investigated in the Gel doc 2000 imaging and analysis system (Bio-Rad, Hercules, CA, USA).

Western blot assays. Cells were washed with chilled PBS for three times and added to lysis buffer M-per mammalian protein extraction to incubate on ice for $30 \mathrm{~min}$. The lysate was then centrifuged at 13,000 $\mathrm{g}$ for $5 \mathrm{~min}$ and the supernatant was collected. Concentration of total proteins was determined with the Bradford protein assay kit. Proteins were separated by SDS-PAGE and were transferred to a PVDF membrane. Primary antibodies goat anti-human antibody ERCC1 (1:200) and goat anti-human antibody $\beta$-actin (1:200) were applied to bond with target proteins on the PVDF membrane, and followed by the combination with the secondary antibody rabbit anti-goat (1:500). At last, the bands were identified by the enhanced FITC reagents.

Cell growth curve. Cells $\left(1 \times 10^{4}\right)$ were seeded in 24-well plates with 18 duplications for each cell sample: H1299 cells (parental cells as control), H1299/E cells (transfected with PCDNA3.1ERCC1) and H1299/V cells (transfected with PCDNA3.1 vehicle only). Survival cell of each cell sample were counted in three duplications every day. The procedures were as follows: briefly, culture solution in each well was removed with a straw. Cells left in the well were trypsinized with $100 \mu \mathrm{l}$ $0.25 \%$ trypsin for 3-5 min, and then suspended uniformly with $800 \mu \mathrm{l}$ RPMI-1640 medium and $100 \mu \mathrm{l}$ trypan blue staining. Survival of the cells were evaluated under the inverted microscope (Olympus, Tokyo, Japan). Cell number was calculated according to the formula $\mathrm{N}=(\mathrm{n} / 4) \times 10^{4} \mathrm{xV}$. Finally, cell growth curves were drawn with cell number as the $y$-axis and time as the $\mathrm{x}$-axis.

Colony-forming assays. Cells were uniformly seeded in 24-well plates at the density of 50,100, 200 in triplicate, and cultured at $37^{\circ} \mathrm{C}$ in a humidified atmosphere containing $5 \% \mathrm{CO}_{2}$ for 5-6 days. The culture medium was replaced by fresh medium every 3 days. When colony contained $>50$ cells, it was washed with PBS, fixed with methanol for 15 min and stained with Giemsa for $30 \mathrm{~min}$, then washed with water and dried in an airing chamber. Then, the colony was counted under the Gel doc 2000 imaging and analysis system. Colony forming rate was determined according to the equation: colony forming rate $=($ number of colonies/number of seeded cells $) \times 100 \%$.

Cell cycle analysis. Cell cycle distribution was determined by flow cytometry (FCM). Cells were washed twice with 
PBS and fixed with $1 \mathrm{ml}$ chilled $70 \%$ ethanol at $4^{\circ} \mathrm{C}$ overnight, then washed twice again with PBS and suspended at the density of $1 \times 10^{6} / \mathrm{ml}$ with the staining solution containing $0.05 \mathrm{mg} / \mathrm{ml} \mathrm{PI}$ and $0.1 \mathrm{mg} / \mathrm{ml} \mathrm{RNase} \mathrm{A}$ and incubated in the dark at $4^{\circ} \mathrm{C}$ for $30 \mathrm{~min}$. At the end of the incubation period, the cell suspension was filtered with a 300 mesh screen to remove adhered cells. Finally, DNA content of each cell sample was detected on EPICS XL (Beckman, Urbana, IL, USA) and cell cycle distribution was determined with the muticycle software.

Matrigel invasion assays. Matrigel invasion assays were performed to evaluate the ability of cell invasion in vitro. The lower surface of filter membrane $(8 \mu \mathrm{m})$ of transwells was treated with $50 \mu \mathrm{l}$ PBS supplemented with $5 \mu \mathrm{g}$ fibronectin (Sigma) and dried at room temperature overnight. Matrigel $(50 \mu \mathrm{l})$ that had been diluted to the density of $1.25 \mathrm{mg} / \mathrm{ml}$ with the cold serum-free RPMI-1640 medium was added to the upper surface of the filter membrane, incubating for 4-5 $\mathrm{h}$. Cells, after three washes were trypsinized with $0.25 \%$ trypsin, and resuspended at the density of $1 \times 10^{6} / \mathrm{ml}$ in the RPMI-1640 medium supplemented with $1 \%$ FBS. Cell suspension solution $(100 \mu \mathrm{l})$ was added to the upper chamber of the transwells and $600 \mu \mathrm{l}$ of the medium containing 1\% FBS was added to the lower chamber, incubating at $37^{\circ} \mathrm{C}$ in a humidified atmosphere containing $5 \% \mathrm{CO}_{2}$ for $20-24 \mathrm{~h}$. At the end of incubation period, cells in both chambers were treated with 10 and $60 \mu 1$ of 3-(4,5-dimethylthiazol-2-yl)-2,5-diphenyltetrazolium bromide (MTT, Sigma), followed by 10 min dissolution with DMSO. Matrigel invasion ability of cells was determined through detecting the OD value of the dissolved solution at $450 \mathrm{~nm}$.

Evaluation of cisplatin response. Cisplatin response of cells was determined by MTT assays. Cells $\left(1 \times 10^{5} / \mathrm{ml}\right)$ were trypsinized with $0.25 \%$ EDTA and seeded into 96 -well plates in triplicate. After incubated for $24 \mathrm{~h}$, they were treated with different concentrations of cisplatin $(0-400 \mu \mathrm{g} / \mathrm{ml}$ with $50 \mu \mathrm{g} / \mathrm{ml}$ for a gradient) for $24 \mathrm{~h}$. At the end of the treatment period, $20 \mu \mathrm{l}$ of MTT was added into each well and incubated for $4 \mathrm{~h}$. The cells were then collected by the centrifugation and treated with $150 \mu \mathrm{l}$ of DMSO for $10 \mathrm{~min}$. The plates were scanned at $570 \mathrm{~nm}$ in a 96-well plate reader (DG3201, Nanjing, China). Each experiment was conducted three times in triplicate. Rate of inhibition (IR) were calculated by the formula $\operatorname{IR}(\%)=\left(\mathrm{A}_{\text {control }}-\mathrm{A}_{\text {treatment }}\right) / \mathrm{A}_{\text {control }} \times 100 \%$.

Measurement of intercellular drug concentration. Drug accumulation in cells was assessed by detecting intercellular concentration of drugs with HPLC assays. After treated with $14 \mu \mathrm{g} / \mathrm{ml}$ cisplatin or $2 \mu \mathrm{g} / \mathrm{ml}$ adriamycin, cells $\left(1 \times 10^{6}\right)$ were trypsinized and collected by centrifugation. Then cells were suspended with $\mathrm{ddH}_{2} \mathrm{O}$ and lysed through the repeated freeze-thaw cycles. The lysate was centrifuged at $12,000 \mathrm{rpm}$ for $5 \mathrm{~min}$ and the supernatant was collected to be analyzed with HPLC-10A VP (Shimadzu, Kyoto, Japan). The HPLC conditions for cisplatin analysis were as follows: chromatographic column: Shim-pack CLC-ODS (250x4.6 mm, $5 \mu \mathrm{m}$, Shimadzu, Kyoto, Japan); column temperature, $35^{\circ} \mathrm{C}$; mobile phase, distilled water; test wavelength, $230 \mathrm{~nm}$; flow-rate, $1.0 \mathrm{ml} / \mathrm{min}$; and sample size, $10 \mu 1$. For ADM analysis, the
HPLC conditions were chromatographic column: Shim-pack CLC-ODS (250x4.6 $4.6 \mathrm{~mm}, 5 \mu \mathrm{m})$; column temperature, $40^{\circ} \mathrm{C}$; mobile phase, the mixture containing methanol- $0.01 \mathrm{M}$ phosphate and $0.01 \%$ sodium dodecyl sulfate $(\mathrm{v} / \mathrm{v}=85 / 15)$, adjusted to $\mathrm{pH} 2.5$ with phosphoric acid; wavelength, $545 \mathrm{~nm}$; flow-rate, $1.3 \mathrm{ml} / \mathrm{min}$ and sample size, $20 \mu \mathrm{l}$.

Detection of the expression of cell membrane proteins. Expression of two membrane proteins, P-gp and MRP, were detected by the FCM. Cells were adjusted to the density of $5 \times 10^{6}-1 \times 10^{7} / \mathrm{ml}$ with RPMI-1640 medium. Then, $100 \mu 1$ of the cell suspension was mixed with $50 \mu \mathrm{l}$ of the inactivated normal rabbit serum followed by the 10 -min incubation at $4^{\circ} \mathrm{C}$. At the end of incubation period, it was washed twice and centrifuged at $1,000 \mathrm{rpm}$ for $5 \mathrm{~min}$, and the supernatant was discarded. Then 5-50 $\mu 1$ of the chilled mouse antihuman $\mathrm{McAb}$ was added and incubated at $4^{\circ} \mathrm{C}$ for $30 \mathrm{~min}$. After washed twice and centrifuged at 1,000 rpm for $5 \mathrm{~min}$, the cells were suspended with $50 \mu 1$ of the goat anti-mouse secondary antibody with fluorescent marker and incubated at $4^{\circ} \mathrm{C}$ for $30 \mathrm{~min}$. After washing and centrifugation, the cells were resuspended with $0.5 \mathrm{ml}$ of PBS, filtered with the 300 mesh screen and finally detected utilizing the FCM.

ERCC1 knockdown in A549 cell line. Human NSCLC cell line A549 with an intrinsic ERCC1 expression was selected as the parental cell in the RNAi experiments. Four small interfering RNAs (siRNAs) targeting to ERCC1 gene were designed according to the principles described previously (29). The sensestrand sequences of siRNA duplexes were as follows: siRNA897: 5'-CAGACCCTCCTGACCACATTTGG-3'; siRNA255: 5'-AAGCCCTTATTCCGATCTACACA-3'; siRNA783: 5'-AAGGCCTATGAGCAGAAACCAGC-3'; siRNA693: 5'-AAGGAGCTGGCTAAGATGTGAT-3'. In addition, one siRNA for the GAPDH gene was designed as a positive control: 5'-GUAUGACAACAGCCUCAAGTT-3', and another siRNA not associated with ERCC1 gene but marked with flourescent indicator was the negative control: 5'-TTCTCCGAACGTGTCACGT-3'. They were synthesized and inserted into the Bam $\mathrm{H} 1$ and HindIII sites of a pSilencer 4.1-CMV-neo vector, respectively, and followed by the transfection into the A549 cells utilizing Lipofectamine 2000. For ERCC1 gene, the gene-specific siRNA with optimal efficiency of interference was selected to be used in the following experiments. mRNA and protein expression of ERCC1 in the three cell samples, A549/E cells transfected with the siRNA of ERCC1, A549/V cells transfected only with the vehicle vector (as a positive control) and the parental A549 cells (as a negative control), was then detected by RT-qPCR and western blot assays, respectively. In addition, cisplatin response of A549/E cells and A549/V cells was also detected according to the above description in 'Evaluation of cisplatin response'. The treatment concentration of cisplatin was $0-80 \mu \mathrm{g} / \mathrm{ml}$ with $10 \mu \mathrm{g} / \mathrm{ml}$ for a gradient.

Statistical analysis. The difference among three groups was calculated by one-way ANOVA, and the difference between two groups was analyzed by Student's t-test. All of the analysis was performed on SPSS 19.0 software. A value of $\mathrm{P}<0.05$ was considered as statistically significant. 

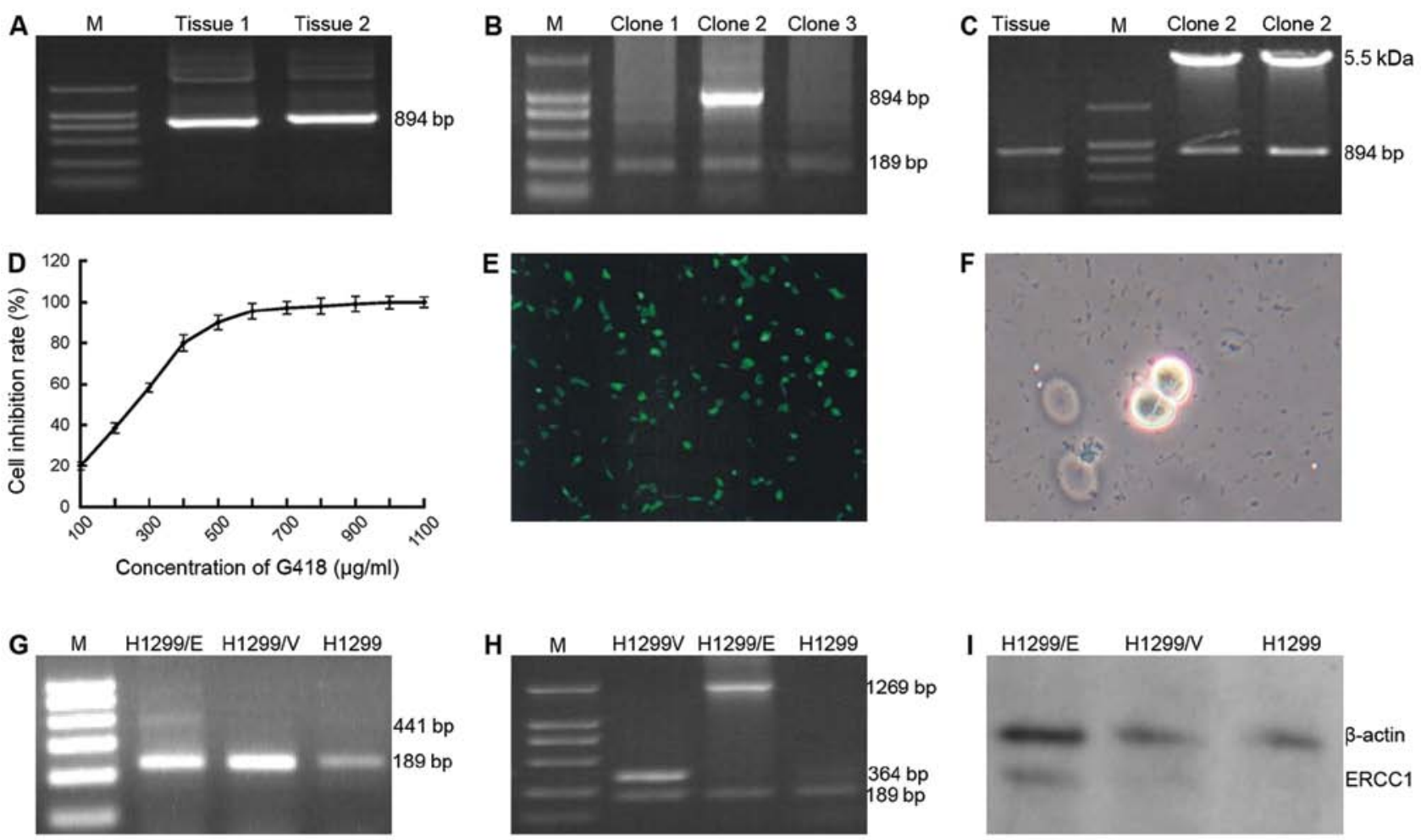

Figure 1. ERCC1 gene was transfected into the NSCLC H1299 cells. Target fragment of ERCC1 gene with 894 bp was obtained from brain tissue samples through RT-PCR technique and then examined by agarose gel electrophoresis test (A). Clones of TOP 10 transfected with the recombinant plasmid of ERCC1PCDNA3.1 were selected by the blue-white selection. A positive marked clone 2 is demonstrated (B) and further confirmed by the restriction enzyme cleave identification (C). The screening concentration of geneticin (G418) used in the following transfection was determined as $600 \mu \mathrm{g} / \mathrm{ml}$ at which the negative clones would be killed (D). The process of transfection was controlled by the comparison of green fluorescent protein (x200) (E). Positive clone of H1299/E was selected utilizing limited dilution method (F) and then cultured to an extended scale. mRNA expression of ERCC1 (441 bp) was demonstrated in the H1299/E cells using RT-PCR with the specific primers of ERCC1 (G). When the specific primers of PCDNA3.1 was employed, the expression of ERCC1-PCDNA3.1 (1269 bp) and PCDNA3.1 (364 bp) was detected in the H1299/E and H1299/V cells, but no expression of either was found in the parental H1299 cells (H). In addition, ERCC1 protein expression was captured by western blot analysis in the H1299/E cells, and not in the H1299/V and H1299 cells (I).

\section{Results}

ERCC1 was successfully transfected into the NSCLC H1299 cells. To investigate the biological functions of ERCC1 on NSCLC cells, ERCC1 gene was cloned and transfected into the NSCLC H1299 cells with no intrinsic ERCC1 expression. ERCC1 gene was attained by RT-PCR technique (Fig. 1A) and linked to the PCDNA3.1 vector, to compose the recombinant plasmid PCDNA3.1-ERCC1 which was transfected into the competent cell TOP 10 treated with chilled $\mathrm{CaCl}_{2}$ solution. Positive TOP 10 clones were screened by blue-white selection and further subject to PCR identification with the primers of ERCC1 gene. As a result, a band of 894 bp coincided with the target gene ERCC1 (Fig. 1B) was successfully amplified in clone 2 which was then selected to the following confirmation assays in which PCR identification was conducted again with the primers of PCDNA3.1. Two bands 894 bp (ERCC1) and $5.5 \mathrm{~kb}$ (PCDNA3.1) were indicated in the result of the restriction enzyme cleave identification (Fig. 1C), which demonstrated that the recombinant plasmid of PCDNA3.1ERCC1 had been successfully cloned.

G418 was used as the screening regent in the following eukaryotic transfection experiments. The screening concentration was determined as $600 \mu \mathrm{g} / \mathrm{ml}$ by the assays of cytotoxic reaction on $\mathrm{H} 1299$ cells (Fig. 1D). The recombinant plasmid PCDNA3.1-ERCC1 and PCDNA3.1 vehicle were, respectively, transfected into the H1299 cells. They were named H1299/E and H1299/V, respectively. H1299 cells transfected with the GFP gene pEGFP-N1 (H1299/GFP cells) and the parental H1299 cells without DNA transfection were the positive and negative controls, respectively. The expression of GFP detected in the H1299/GFP cells (Fig. 1E) indicated that the processes of transfection had been accurately carried out. Following G418 screening with the concentration of $600 \mu \mathrm{g} / \mathrm{ml}$, the living clones (Fig. 1F) were selected and cultured to an extended scale.

Further identification for the transfection was conducted with PCR technique. ERCC1 expression (441 bp) appeared in H1299/E cells not in H1299/V and H1299 cells when the primers of ERCC1 were used in the PCR process (Fig. 1G), by contrast, when the primers of PCDNA3.1 were applied, the expression of ERCC1-PCDNA3.1 (1,269 bp) and PCDNA3.1 (364 bp) were detected in H1299/E and H1299/V cells, respectively, and no expression of either was found in H1299 cells (Fig. 1H). Correspondingly, the protein expression of ERCC1 was also demonstrated in H1299/E cells, not in H1299/V and H1299 cells by the western blot analysis (Fig. 1I). These findings indicated that ERCC1 gene had been successfully transfected into H1299 cells.

ERCC1 expression had no effect on cell proliferation, colonyforming, cell cycle and the ability of invasion in NSCLC H1299 cells. Cell proliferation of H1299/E, H1299/V and H1299 cells 

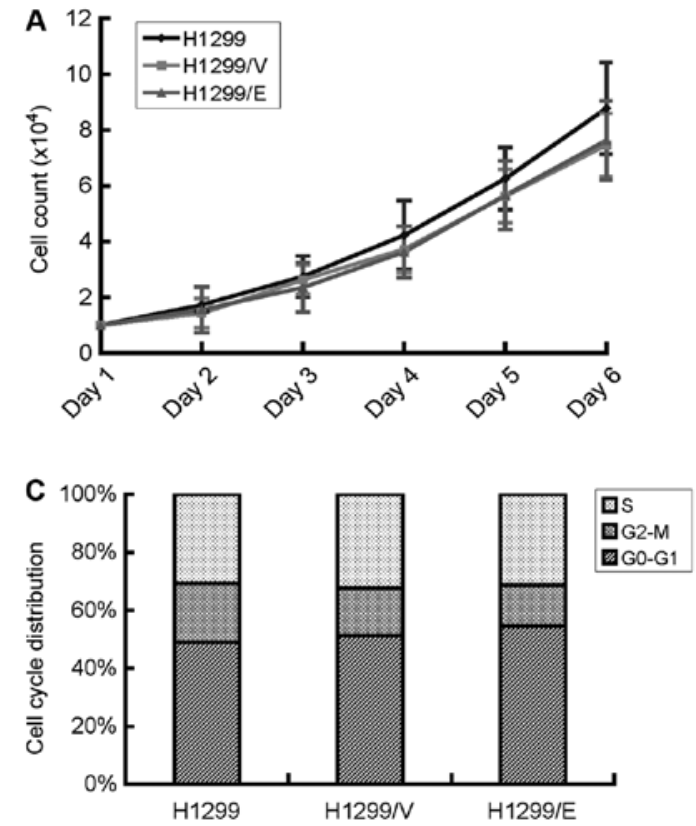
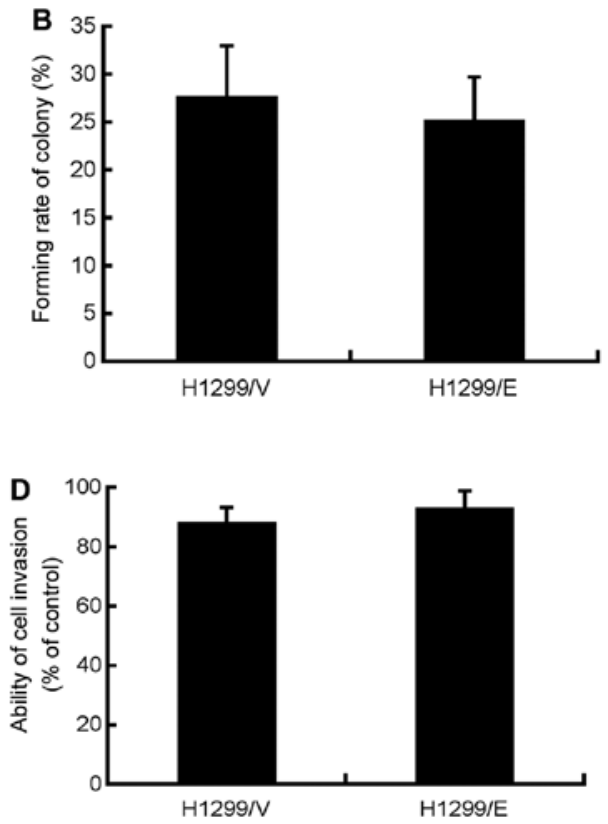

Figure 2. ERCC1 had no effect on cell proliferation, colony-forming rate, cell cycle and the ability of cell invasion. H1299/E, H1299/V and H1299 cells displayed no significant difference in cell proliferation from days $1-5$ with $\mathrm{P}>0.05$, respectively (A). Following 6 -day incubation at $37^{\circ} \mathrm{C}$ in a humidified atmosphere containing 5\% $\mathrm{CO}_{2}, \mathrm{H} 1299 / \mathrm{V}$ and $\mathrm{H} 1299 / \mathrm{E}$ cells exhibited no significant difference in colony-forming rate with P>0.05 (B). No difference was found in cell cycle distribution (C) and cell invasion (D) among H1299/E, H1299/V and H1299 cells with P>0.05, respectively.

was evaluated by survival cell count assays. H1299/E and H1299/V cells displayed a similar tendency in the growth curve, they showed no significant difference with their parental cells H1299 in growth rate with $\mathrm{P}>0.05$, although they had a slightly slower growth compared with the parental cells (Fig. 2A). Therefore, cell proliferation of NSCLC H1299 cells in the present study was not affected by the expression of ERCC1.

Colony-forming assays were also employed to examine the ability of cell proliferation as well as the population dependence of H1299/E and H1299/V cells. Consequently, the two cell lines exhibited no significant difference in the colony-forming rate with $25.1 \pm 4.6$ and $27.6 \pm 5.4 \%$, respectively and $P>0.05$ (Fig. 2B). The finding demonstrated that ERCC1 expression had no effect on the deterioration of the H1299 cells.

Cell cycle distribution in each cell lines of H1299/E, $\mathrm{H} 1299 / \mathrm{V}$ and 1299 was examined by FCM technique. The results suggested that there was no significant difference in cell cycle distribution among the three cell lines (Fig. 2C), indicating that the expression of ERCC1 had no effect on the cell cycle of the H1299 cells.

Cell invasion is a common biological behavior of cancer cells and was investigated by Matrigel invasion assays in the present study. The invasive ability of the cells was determined by the ratio of the cells in the upper and lower surface of the transwell. Then, the relatively invasive ability of H1299/E and H1299/V cells compared with their parental H1299 cell was calculated, respectively. There was no significant difference in the invasive ability between H1299/E and H1299/V cells (Fig. 2D). The finding indicated that the expression of ERCC1 did not affect the invasive ability of H1299 cells in vitro.

Acquired cisplatin resistance of $H 1299$ cells was associated with ERCC1 expression, but not correlated with the expression of P-gp and MRP proteins. MTT assays were performed to detect the response of $\mathrm{H} 1299 / \mathrm{E}$ and $\mathrm{H} 1299 / \mathrm{V}$ cells to cisplatin, respectively. The $\mathrm{IC}_{50}$ of cisplatin in the H1299/E cells was $186 \mu \mathrm{g} / \mathrm{ml}, 4.23$ times higher than that of $\mathrm{H} 1299 / \mathrm{V}$ cells which was only $44 \mu \mathrm{g} / \mathrm{ml}$ (Fig. 3A). The results suggested that H1299 cells developed an evident cisplatin resistance after transfection with ERCC1 gene.

To clarify whether the acquired cisplatin resistance of H1299/E cells was correlated with drug influx or efflux, intercellular accumulation of cisplatin in H1299/E and H1299/V cells was detected by means of HPLC. Firstly, the standard curve for cisplatin was established with the correlation coefficient of 0.9999, suggesting that the detection system of HPLC with a high confidence was available. Then, intercellular cisplatin concentration in H1299/E and H1299/V cells was tested and calculated based on the established standard curve. They were 3.41 and $4.24 \mu \mathrm{g} / \mathrm{ml}$, respectively, with no significant difference between the two cell lines ( $\mathrm{P}>0.05$, Fig. 3B). By contrast, intercellular concentration of ADM in the two cell lines was determined as well, and the same result was obtained, which indicated that the results produced by HPLC for cisplatin was credible. Consequently, the resistance of H1299/E cells to cisplatin in the present study may be not associated with drug influx or efflux.

As further confirmation of the above, we detected the expression of the associated membrane proteins, P-gp and MRP, which have been reported to participate in drug resistance (12). The FCM result showed that there was no significant difference in the expression of P-gp and MRP proteins between H1299/E and H1299/V cells. Therefore, cisplatin resistance of H1299/E cells in the present study may be not associated with the expression of P-gp and MRP proteins.

ERCC1 expression was interfered with by siRNA in NSCLC A549 cells. To further confirm the effect of ERCC1 expression 


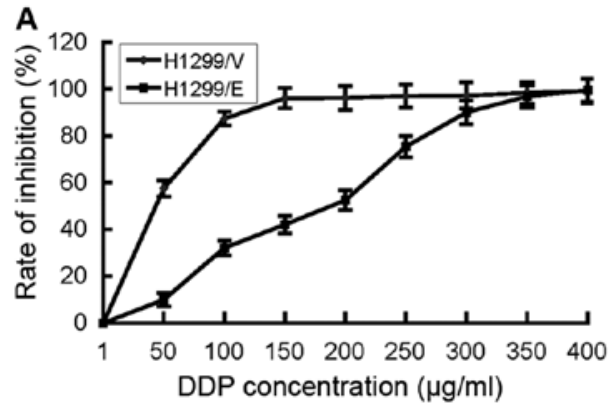

B
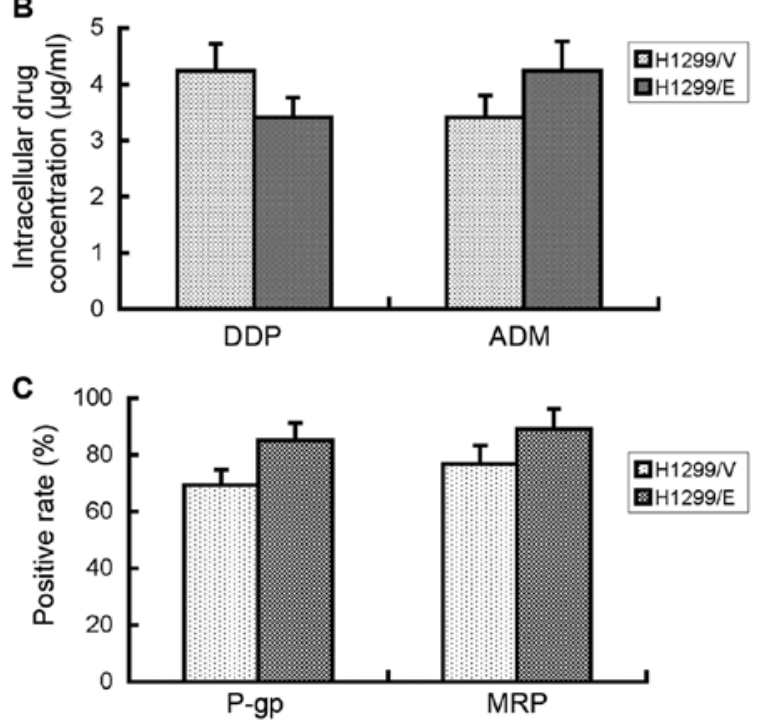

Figure 3. The acquired cisplatin resistance of H1299 cells was associated with the ERCC1 expression but not correlated with drug influx and efflux mediated by membrane proteins. The reaction of H1299/E and H1299/V cells to cisplatin (DDP) was detected by MTT assays, 50\% inhibitive concentration $\left(\mathrm{IC}_{50}\right)$ of DDP in the H1299/E cells $(186 \mu \mathrm{g} / \mathrm{ml})$ was 4.23 times higher than that of H1299/V cells (44 $\mu \mathrm{g} / \mathrm{ml})$ (A). However, intracellular concentration of DDP and ADM determined by HPLC displayed no significant difference between the two cell lines, respectively (B). Correspondingly, the expression of the associated proteins, P-glycoprotein (P-gp) and multidrug resistanceassociated protein (MRP), had no significant difference as well between the two cell lines $(\mathrm{C})$.

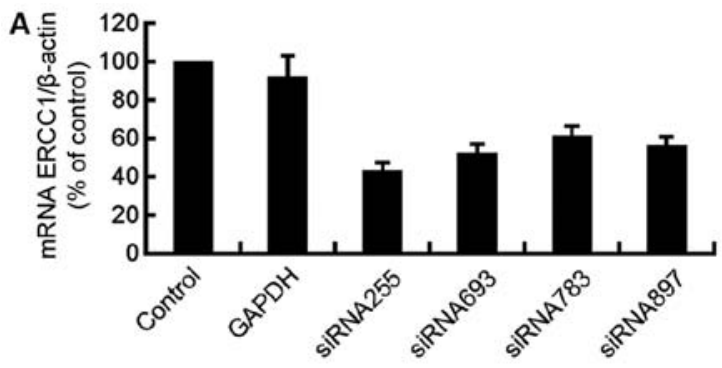

B
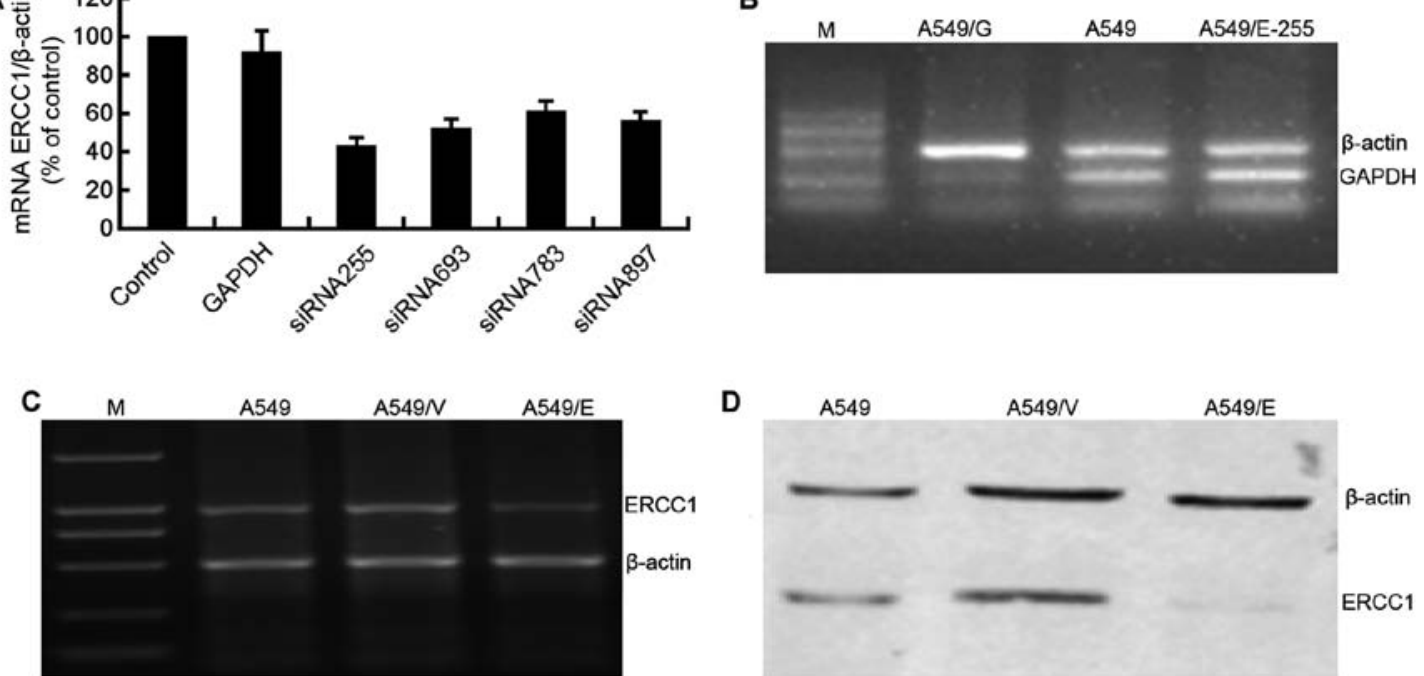

D

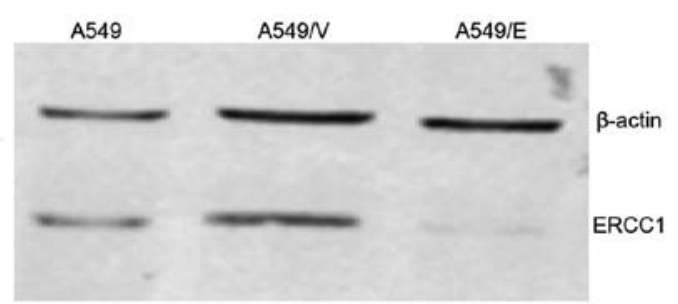

Figure 4. ERCC1 expression was silenced by siRNA utilizing RNAi technique. Four siRNAs to ERCC1 gene were designed, synthesized and transfected into NSCLC A549 cells to interfere with the expression of ERCC1, one siRNA that targets GAPDH was designed and transfected into the A549 cell as the positive control (A549/G), and parental A549 cell without transfection was the negative control. siRNA255 shows the strongest inhibition to ERCC1 expression (A). The inhibition of the GAPDH expression in A549/G cells demonstrated the effectiveness of the transfection processes (B). ERCC1 gene (C) and protein (D) expression was suppressed by siRNA255 in A549/E cells. 


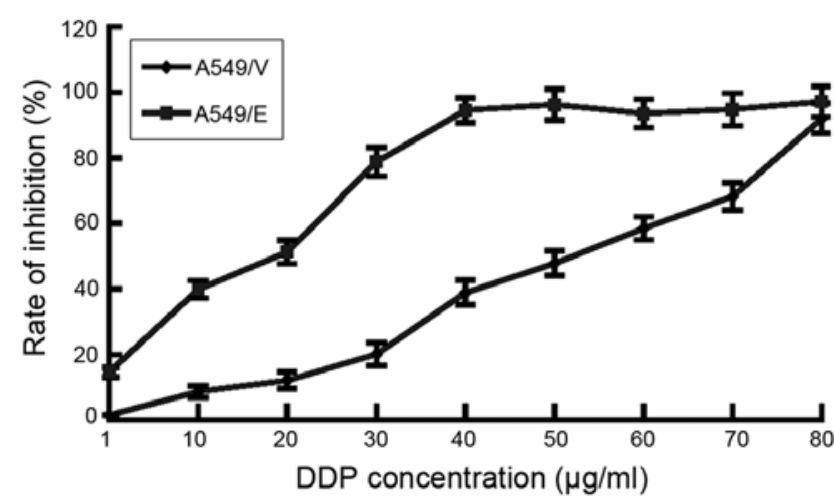

Figure 5. siRNA-induced suppression of ERCC1 evidently enhanced the sensitivity of A549 cell to cisplatin. $\mathrm{IC}_{50}$ to DDP of the A549/E cells was $18.2 \mu \mathrm{g} / \mathrm{ml}$ which was much less than that of the A549/V cells $53.4 \mu \mathrm{g} / \mathrm{ml}$.

variations with platinum-based chemotherapy response and resistance (30-33). Although an exact conclusion has not been made due to the differences of these studies in trial design and laboratory tests $(24,34)$, ERCC1 has attracted great attention of the NSCLC investigators. Studies are underway to determine further correlations between ERCC1 and platinumbased chemotherapy, as well as the underlying mechanisms of platinum resistance in NSCLC treatment (12).

Previous $(30,31)$ including our studies $(28)$ indicated that mRNA and protein expression of ERCC1 in NSCLC tumors was higher than that in adjacent normal tissues, so it was reported that ERCC1 may be associated with the development of NSCLC. As further confirmation, in the present study, ERCC1 gene was cloned and transfected into the NSCLC H1299 cells with no intrinsic ERCC1 expression. Then, H1299/E cells with a stable ERCC1 expression was established (Fig. 1). The effect of ERCC1 expression on cell proliferation, colony-forming rate, cell cycle distribution and the invasion ability of cells were assessed, respectively. However, no significant influence was seen on these aspects through the comparison among H1299/E, H1299/V and their parental H1299 cells (Fig. 2), suggesting that ERCC1 might not directly participate in the processes of cell proliferation, cell cycle and invasion, or correlated with the NSCLC development.

Furthermore, in previous studies $(28,30)$, patients with high ERCC1 expression were considered to obtain less benefit from the platinum-based chemotherapy than those with low ERCC1 expression, which indicated that ERCC1 may be involved in the mechanisms of platinum resistance in NSCLC treatment. In the present study, the $\mathrm{IC}_{50}$ of cisplatin in H1299/E cells was 4.23 times higher than that of H1299/V cells (Fig.3A), suggesting that the expression of ERCC1 in H1299/E cells significantly enhanced the cisplatin resistance of the H1299 cells.

Drug resistance of cancer cells primarily attribute to two mechanisms: one is the decreased effective concentration of drugs in the cell which is induced by the altered cell membrane proteins that work as the drug pumps to decrease drug influx into cells and/or increase drug efflux out of cells (12); the other is the decreased sensitivity of the cancer cell to drugs which is mediated by the increased capacity of DNA repair pathways $(35,36)$. In the present study, no significant difference was found in the accumulation of cisplatin between H1299/E and H1299/V cells (Fig. 3B), furthermore, the expression of P-gp and MRP (12,35), considered as the crucial drug efflux pumps, had no significant difference between the two cell lines (Fig. 3C). The findings demonstrated that the acquired cisplatin resistance of H1299/E cells predominately attributed to the expression of ERCC1.

To further confirm the impact of ERCC1 on the sensitivity of NSCLC cells to cisplatin, another NSCLC cell line A549 with intrinsic expression of ERCC1 was selected, and the ERCC1 gene was interfered with utilizing RNAi technique. A549/E cell line with the silenced ERCC1 expression was established (Fig. 4). $\mathrm{IC}_{50}$ of cisplatin in A549/E cells decreased by two-thirds compared with A549/V cells in which ERCC1 expression was not silenced, suggesting that the interference of ERCC1 expression increased the sensitivity to cisplatin for NSCLC cells. This agreed with the results of Chang et al that the siRNA-induced suppression of ERCC1 enhancing sensitivity of HeLa S3, MCF-7, and HCT116 cells to cisplatin (37). These findings confirmed that ERCC1 is a chemotherapytolerating gene in the cisplatin-based treatment for human cancer cells.

In conclusion, based on the above and previous findings that mRNA and protein expression of ERCC1 correlates with survival of NSCLC patients as well as outcomes of platinum-based treatment, in the present study, we further investigated the biological functions of ERCC1 in the physiological processes of NSCLC cells by cloning, transfection and RNAi technique. ERCC1 had no effect on cell proliferation, cell cycle and invasion but exhibited significant impact on cisplatin response of NSCLC cells. The results demonstrated that ERCC1 might not directly participate in the physiological processes but its high expression enhanced the resistance of NSCLC cells to cisplatin. Therefore, we concluded that ERCC1 is a chemotherapy-tolerating gene in cisplatin-based treatment of NSCLC. Although ERCC1 is a promising biomarker for NSCLC treatment, a wide range of preclinical and clinical studies should be conducted before its clinical use.

\section{Acknowledgements}

This study was supported by grant from the project of Guangxi Science Foundation (no. 0832077).

\section{References}

1. Le Chevalier T: Adjuvant chemotherapy for resectable non-smallcell lung cancer: where is it going? Ann Oncol 21 (Suppl 7): vii196-vii198, 2010.

2. Azzoli CG, Park BJ, Pao W, Zakowski M and Kris MG: Molecularly tailored adjuvant chemotherapy for resected non-small cell lung cancer: a time for excitement and equipoise. J Thorac Oncol 3: 84-93, 2008

3. Dziadziuszko R and Hirsch FR: Advances in genomic and proteomic studies of non-small-cell lung cancer: clinical and translational research perspective. Clin Lung Cancer 9: 78-84, 2008.

4. TailladeL,Penault-LlorcaF,BouletT,etal:Immunohistochemichal expression of biomarkers: a comparative study between diagnostic bronchial biopsies and surgical specimens of non-small cell lung cancer. Ann Oncol 18: 1043-1050, 2007.

5. Toschi L and Cappuzzo F: Impact of biomarkers on non-small cell lung cancer treatment. Target Oncol 5: 5-17, 2010.

6. Bowden NA: Nucleotide excision repair: why is it not used to predict response to platinum-based chemotherapy? Cancer Lett 346: 163-171, 2014. 
7. Simon GR, Ismail-Khan R and Bepler G: Nuclear excision repair-based personalized therapy for non-small cell lung cancer: from hypothesis to reality. Int J Biochem Cell Biol 39: 1318-1328, 2007.

8. Rosell R, Lord RV, Taron M and Reguart N: DNA repair and cisplatin resistance in non-small-cell lung cancer. Lung Cancer 38: 217-227, 2002.

9. Friboulet L, Barrios-Gonzales D, Commo F, et al: Molecular characteristics of ERCC1-negative versus ERCC1-positive tumors in resected NSCLC. Clin Cancer Res 17: 5562-5572, 2011.

10. Bepler G: Pharmacogenomics: a reality or still a promise? Lung Cancer 54 (Suppl 2): S3-S7, 2006

11. Custodio A, Mendez M and Provencio M: Targeted therapies for advanced non-small-cell lung cancer: current status and future implications. Cancer Treat Rev 38: 36-53, 2012.

12. Stewart DJ: Tumor and host factors that may limit efficacy of chemotherapy in non-small cell and small cell lung cancer. Crit Rev Oncol Hematol 75: 173-234, 2010.

13. Gossage L and Madhusudan S: Current status of excision repair cross complementing-group 1 (ERCC1) in cancer. Cancer Treat Rev 33: 565-577, 2007.

14. Rosell R, Vergnenegre A, Liu B, et al: Biomarkers in lung oncology. Pulm Pharmacol Ther 23: 508-514, 2010.

15. Chen J, Emara N, Solomides C, Parekh H and Simpkins H: Resistance to platinum-based chemotherapy in lung cancer cell lines. Cancer Chemother Pharmacol 66: 1103-1111, 2010.

16. Rosell R, Cobo M, Isla D, Camps C and Massuti B: Pharmacogenomics and gemcitabine. Ann Oncol 17 (Suppl 5): v13-v16, 2006.

17. O'Brien CP, Taylor SE, O'Leary JJ and Finn SP: Molecular testing in oncology: problems, pitfalls and progress. Lung Cancer 83: 309-315, 2014

18. Olaussen KA, Dunant A, Fouret P, et al: DNA repair by ERCC1 in non-small-cell lung cancer and cisplatin-based adjuvant chemotherapy. N Engl J Med 355: 983-991, 2006.

19. Takenaka T, Yoshino I, Kouso H, et al: Combined evaluation of Rad51 and ERCC1 expressions for sensitivity to platinum agents in non-small cell lung cancer. Int J Cancer 121: 895-900, 2007.

20. Tiseo M, Bordi P, Bortesi B, et al: A ERCC1/BRCA1 expression and gene polymorphisms as prognostic and predictive factors in advanced NSCLC treated with or without cisplatin. Br J Cancer 108: 1695-1703, 2013

21. Rosell R, Cecere F, Santarpia M, Reguart N and Taron M: Predicting the outcome of chemotherapy for lung cancer. Curr Opin Pharmacol 6: 323-331, 2006.

22. Ota S, Ishii G, Goto $\mathrm{K}$, et al: Immunohistochemical expression of BCRP and ERCC1 in biopsy specimen predicts survival in advanced non-small-cell lung cancer treated with cisplatin-based chemotherapy. Lung Cancer 64: 98-104, 2009.

23. Wachters FM, Wong LS, Timens W, Kampinga $\mathrm{HH}$ and Groen HJ: ERCC1, hRad51 and BRCA1 protein expression in relation to tumour response and survival of stage III/IV NSCLC patients treated with chemotherapy. Lung Cancer 50: 211-219, 2005.
24. Filipits $\mathrm{M}$ and Pirker R: Predictive markers in the adjuvant therapy of non-small cell lung cancer. Lung Cancer 74: 355-363, 2011.

25. Filipits M, Haddad V, Schmid K, et al: Multidrug resistance proteins do not predict benefit of adjuvant chemotherapy in patients with completely resected non-small cell lung cancer: International Adjuvant Lung Cancer Trial Biologic Program. Clin Cancer Res 13: 3892-3898, 2007.

26. Voortman J, Goto A, Mendiboure J, et al: MicroRNA expression and clinical outcomes in patients treated with adjuvant chemotherapy after complete resection of non-small cell lung carcinoma. Cancer Res 70: 8288-8298, 2010.

27. Filipits M, Pirker R, Dunant A, et al: Cell cycle regulators and outcome of adjuvant cisplatin-based chemotherapy in completely resected non-small-cell lung cancer: the International Adjuvant Lung Cancer Trial Biologic Program. J Clin Oncol 25: 2735-2740, 2007.

28. Pan H, Li L, Zuo CT, Mao NQ, Chen FL, Zhang W and Tang BJ: Relationship between combined multigene detection and response to adjuvant chemotherapy in early-stage non-small cell lung cancer. Zhonghua Zhong Liu Za Zhi 30: 528-531, 2008

29. Elbashir SM, Lendeckel $W$ and Tuschl T: RNA interference is mediated by 21- and 22-nucleotide RNAs. Genes Dev 15: 188-200, 2001

30. Jiang J, Liang X, Zhou X, Huang R, Chu Z and Zhan Q: ERCC1 expression as a prognostic and predictive factor in patients with non-small cell lung cancer: a meta-analysis. Mol Biol Rep 39: 6933-6942, 2012

31. Tepeli E, Caner V, Buyukpinarbasili N, Cetin GO, Duzcan F, Elmas L and Bagci G: Expression of ERCC1 and its clinicopathological correlations in non-small cell lung cancer. Mol Biol Rep 39: 335-341, 2012.

32. Koc E, Caner V, Buyukpinarbasili N, Tepeli E, Turk NS Ozan Cetin G and Bagci G: The determination of relationship between 'excision repair cross-complementing group 1' (ERCC1) gene T19007C and C8092A single nucleotide polymorphisms and clinicopathological parameters in non-small cell lung cancer. Mol Biol Rep 39: 375-380, 2012.

33. Yang Y and Xian L: The association between the ERCC1/2 polymorphisms and the clinical outcomes of the platinumbased chemotherapy in non-small cell lung cancer (NSCLC): a systematic review and meta-analysis. Tumour Biol 35: 29052921, 2014.

34. Friboulet L, Olaussen KA, Pignon JP, et al: ERCC1 isoform expression and DNA repair in non-small-cell lung cancer. N Engl J Med 368: 1101-1110, 2013.

35. Rabik CA and Dolan ME: Molecular mechanisms of resistance and toxicity associated with platinating agents. Cancer Treat Rev 33: 9-23, 2007.

36. Altaha R, Liang X, Yu JJ and Reed E: Excision repair cross complementing-group 1: gene expression and platinum resistance. Int J Mol Med 14: 959-970, 2004.

37. Chang IY, Kim MH, Kim HB, Lee DY, Kim SH, Kim HY and You HJ: Small interfering RNA-induced suppression of ERCC1 enhances sensitivity of human cancer cells to cisplatin. Biochem Biophys Res Commun 327: 225-233, 2005. 